\title{
Nursing students gain tools for knowledge utilisation through a work and research integrated learning assignment - a qualitative study
}

\author{
Albert Westergren, Ellinor Edfors \\ The PRO-CARE Group, School of Health and Society, Kristianstad University, Sweden \\ Correspondence: Albert Westergren. Address: School of Health and Society, Kristianstad University, SE-291 88 \\ Kristianstad, Sweden. Telephone: 46-44-208-550. Email: Albert.Westergren@hkr.se.
}

Received: May 11, 2012

DOI : $10.5430 /$ jnep.v3n1p60

Published: January 1, 2013

Accepted: August 27, 2012

3n1p60

\section{Abstract}

Background: By integrating education, research and collaboration with society, in a learning assignment, the level of nursing students learning can be enhanced.

Aim: The purpose of this study was to explore nursing students' experiences of participating in a work and research integrated learning assignment during their clinical practice courses.

Methods: At the end of their nursing training, in their sixth semester, five nursing students were recruited to the study and interviewed after which the texts of interviews were analysed using content analysis. The participants had been involved in two studies, one during their second semester, where the risk of falling was assessed, and one during their sixth semester where the risk for under nutrition was assessed.

Results: The students experienced that the two assignments enhanced their learning in how to work as a foreman/supervisor, how to inform and engage in dialogue, about using risk assessment, and further, gave them the opportunity to meet the people behind the diagnosis. Through assignments they could also identify the need for knowledge within the study focus, for instance, the risks for falling or the risk of undernourishment. Further, they described how they tried to live up to the ethical standards and that they had learned about using a scientific approach in their work.

Conclusion: It is possible to integrate Research, Education and Collaboration in a learning assignment during Nursing education (RECN-assignment) by allowing nursing students to participate in an actual research project during their work integrated learning courses. Such an approach enhances nursing students learning about research and the area being studied in the actual research project.

\section{Key words}

Work integrated learning, Knowledge utilization, Nursing education

\section{Introduction}

Swedish higher education is built on several corner-stones; research, education and collaboration with the immediate society ${ }^{[1]}$. The nursing degree programme comprises of both theoretical and clinical practice courses. Clinical practice courses integrate foremost, education and collaboration while research is a more neglected area ${ }^{[2]}$. 
All Swedish health care practice shall be based on science and well-proven clinical experience ${ }^{[3]}$. In the Swedish description of the competences required for registered nurses, it becomes clear that the prerequisite to be able to provide good care is based on a value system that is characterised by a holistic and ethical approach, and an ability to seek and use evidence-based knowledge ${ }^{[4]}$. Despite this fact, almost nine percent of patients suffer from health care related injuries in Swedish somatic inpatient care. Nine percent of these injuries lead to permanent disability and three percent to death ${ }^{[5]}$. Even though it is not possible from that study to quantify the number of health care related injuries caused by inappropriate nursing, it can be assumed that health care professionals, including nurses, do not always apply evidence based knowledge in their care assignments. For instance, Forsman and colleagues ${ }^{[6]}$ revealed quite a low research use (direct, indirect, persuasive) among nurses, one $(\mathrm{n}=1365)$ and three years after graduation $(\mathrm{n}=933)$. Low and very low research use were common both at one (45.6\%) and three (51.6\%) years postgraduation ${ }^{[6]}$.

Lack of research utilisation is well described in different disciplines and several studies highlight barriers to, and facilitators for, research utilisation in nursing care ${ }^{[7-10]}$. Studies have shown that it was a complexity of multiple factors that was affecting nurses' research utilisation. In one review ${ }^{[10]}$ six contextual factors relating to research utilisation were identified, the role of the nurse, access to resources, organisational climate, support, time for research activities, and provision of education. In another review, Estabrooks and colleagues ${ }^{[7]}$ identified six individual determinants for research utilisation; beliefs and attitudes, involvement in research activities, information seeking, professional characteristics, education, and other socioeconomic factors. Kocaman and colleagues ${ }^{[8]}$ described that the most commonly perceived barrier to research utilisation by nurses was lack of time. In addition, Thompson and colleagues ${ }^{[9]}$ studied the concept of lack of time in order to understand the relationship between being busy and nurses research utilisation and found that one barrier to research utilisation was a "culture of being busy" in which physical performance was valued higher than time spent reading or reflecting ${ }^{[9]}$. Thus, there are several factors affecting research utilisation by nurses and among these factors are education and involvement in research activities ${ }^{[7]}$. It might enhance research utilisation in their future profession as registered nurses, if nursing students become involved in actual research projects during their nursing education.

The gap between theory and practice in nurse education is under debate and studies which have shown that this gap is related to the organisation and communication of research ${ }^{[11]}$, sequencing of theory and practice, and a lack of collaboration between clinical practice and the education institutions ${ }^{[12]}$. Nursing students felt that they did not understand the meaning of the research education, especially in their primary courses ${ }^{[13,14]}$. Instead of education related to research, they wished to have more practical training ${ }^{[15]}$. However, this view changed to a greater understanding of the value of scientific method and research utilisation, once the students, during their clinical practice, had participated in a real research project ${ }^{[14]}$ and had fulfilled a learning task in the form of an oral presentation and discussion around a nursing research article ${ }^{[15]}$. Allan and Smith ${ }^{[16]}$ have discussed the difficulties in education related to research in nursing programmes and argue for the need for new methods for knowledge transfer, where knowledge learned in a theoretical context can be re-contextualised in the workplace ${ }^{[16]}$. It seems important to provide nursing students with tools for research utilisation for their forthcoming nursing profession in order to ensure patient safety. By doing so, during the student nurses' education, the health care service will possibly also benefit from new ideas created towards how to achieve evidence based quality improvements for patient safety. Possibly, learning assignments that manage to integrate research, education and collaboration with health care facilities have the potential to achieve such goals.

\section{Aim}

The purpose of this study was to explore nursing students' experiences of participating in a work and research integrated learning assignment during clinical practice courses. 


\section{Methods}

\subsection{Study design}

The study had a qualitative design, using interviews ${ }^{[17]}$.

\subsection{Context}

This study was carried out at a university in southern Sweden. In Sweden the nursing education programme takes three years and the theoretical and practical clinical courses consecutively take about one and a half years each. During clinical practise courses (the second and sixth semester), the students participate in a research project focusing on patient safety and quality assurance work. These projects have been conducted every semester since 2005 in collaboration with the research group Patient Reported Outcomes - Clinical Assessment Research \& Education, PRO-CARE (www.hkr.se/ procare). The PRO-CARE group (including two professors, four Ph.D. students, three with MSci, and one research coordinator) selects the focus of the studies and established assessment instruments that shall be used. The purpose for having the students participate is to exemplify how research could be done in practice, to stimulate critical thinking and reflection, and to increase knowledge about structured assessment instruments and how these can be used to identify risks in health care. This study was implemented at a certain date on the wards where the students were receiving their clinical training. The students were responsible for the activities with support from their supervisors and teachers. On wards where there were students from both semesters, the students in their sixth semester acted as supervisors to the students in their second semester.

The nursing students got written and oral information (one hour) about the study. The written information included study background, aim, instruments and procedures and was provided by the PRO-CARE group. Students were also provided with an information letter to the managers as well as another one to the patients. The patients got both information in written as well as orally.

Each student's assignment was to prepare data collection, inform staff (a couple of weeks before data collection) and patients (the day before or same day as data collection), and to collect data using structured assessment instruments (during one day). Data was collected through observations, structured interviews, and medical records. The student should then analyse the results and reflect on them and then report them to the staff with proposals for measures to improve the quality of care (within a couple of days). The PRO-CARE group made suggestions for how to report and discuss the results with the staff. As examples: How was it to use the assessment tool? If a patient was found to be at risk - did he/she get the right treatment? If a patient was found to be at risk - had it been noticed/documented before the study?

The nursing students in this study had been involved in two previous studies, one during their second semester, when the risks for falling was assessed (using the Downton Fall Risk Index ${ }^{[18]}$ ) and one during their sixth semester, when the risk for under nutrition was assessed (using the Minimal Eating Observation and Nutrition Form (MEONF) ${ }^{[19-21]}$ ).

\subsection{Sample}

Interviews were conducted with five female students who had recently participated in a project during their sixth semester Three of the students were placed on hospital wards and two at local nursing homes. The participants were recruited by their clinical teachers and given written information about the study. The goal was to recruit both students that were positive as well as those that were negative towards the study, as experienced by the clinical teachers.

\subsection{I nterviews}

The interviews were conducted as semi-structured interviews ${ }^{[17]}$ based on the study purpose and focused on the participants learning from taking part in a real research project. 
The participants were contacted by phone and further information about the study was given to them and a time and place for the interview was set. The interview began with an open-ended question and the participant was asked to talk freely about her experiences of having participated in the project. Throughout the interview, the author tried to capture the importance related to the aim of the study by using follow-up questions. Examples of follow-up questions: How did participation influence your understanding of research? How did participation influence your knowledge within the area studied in the research project (fall risk and/or nutrition)? The interviews were conducted by the second author (EE), lasted between 40 and 50 minutes, and were recorded with digital equipment and transcribed verbatim.

\subsection{Analysis}

The interview texts were analysed by using qualitative content analysis ${ }^{[22]}$. There are two levels of content analysis: the manifest content analysis that focuses on the content of the texts from a superficial perspective based on the written word, and the latent content analysis that goes in depth with the content and interprets the underlying meaning conveyed by the text ${ }^{[22]}$. In this study the analysis has mainly been based on the manifest content analysis. All the stages of the analysis were conducted by the two authors and the work continuously oscillated between the whole and parts of the collected material. In step one, the texts were read and re-read as a whole, a so-called naive reading. A statement was then made based on the impressions of, and reflections about, the wholeness and the important elements in the text. Step two started with an open coding, i.e. individual words were recorded in the margin. Then all parts of the text relating to the purpose of the study were divided into meaning units. In step three the meaning units were condensed and a number of categories that covered the codes and the condensed meaning units emerged. In the fourth step all texts were re-read and compared with the outcome of the analysis to ensure that the categories covered the content of the texts. "Open Code" (freeware) was used as software for the qualitative analysis (UMDAC and Epidemiology, University of Umeå, Sweden).

\subsection{Ethical considerations}

According to Swedish law ${ }^{[23]}$, no ethical approval is required for this type of study. The participants were given both oral and written information about the purpose of the study and their informed consent was obtained. They were informed that participation was voluntary, that they could withdraw at any time and that the data would be treated as confidential.

\section{Results}

Recurrent in the interviews was the fact that the participants' felt themselves as being special since they were apparently regarded as being competent enough to participate in a real research project. Furthermore, the participants found it valuable that they themselves were responsible for the implementation of the project without any involvement of their supervisor or teacher. Also, they found it positive that they were free from their regular work so that they could give their full attention to the research assignment.

Seven categories emerged from the analysis of the texts: to be a foreman/supervisor; to inform and engage in dialogue; to use risk assessment; to meet the person behind the diagnosis; to identify the need for knowledge; to live up to ethical standards; and to work from a scientific approach (see Table 1).

Table 1. Categories with illustrative quotations

\begin{tabular}{ll}
\hline Category & Quotations \\
\hline I got the opportunity to supervise and to be in charge (interview 1) \\
It was fun to be a supervisor. I felt responsible. They were willing to learn and listen to what you had \\
to say (interview 4) \\
I did not get the opportunity to supervise that much, but I cooperated with the nurse assistants \\
(interview 5)
\end{tabular}

(Table 1 continued on page 64) 
Table 1. (continued)

\begin{tabular}{|c|c|}
\hline Category & Quotations \\
\hline $\begin{array}{l}\text { To inform and engage in } \\
\text { dialogue }\end{array}$ & $\begin{array}{l}\text { We put a summary of the findings at the office and gave one to the ward manager but we got no } \\
\text { feed-back (interview 4) } \\
\text { The staff were interested which awoke discussion. One nurse responded: Wow! (interview 5) }\end{array}$ \\
\hline To use risk assessment & $\begin{array}{l}\text { Good with structured assessment. It provides more than conversation (interview 1) } \\
\text { To get so much out from only a few questions! (interview 3) } \\
\text { It is good to use structured assessments, then to ad clinical look, follow-up questions, and reflection } \\
\text { - a comprehensive view is important (interview 4) } \\
\text { It is important to engage the patient in the assessment and discussion - in itself it limits the risk } \\
\text { (interview 5) }\end{array}$ \\
\hline $\begin{array}{l}\text { To meet the person behind } \\
\text { the diagnosis }\end{array}$ & $\begin{array}{l}\text { The patients appreciated the social intercourse (interview 2) } \\
\text { I took time to talk with the patients - about the body, life, and such things (interview 3) } \\
\text { Through this I got to know much more about the patient. By talking and observing (interview 5) }\end{array}$ \\
\hline $\begin{array}{l}\text { To identify the need for } \\
\text { knowledge }\end{array}$ & $\begin{array}{l}\text { I saw my knowledge gaps, something I have since deepened (interview 1) } \\
\text { I learnt to be critical and about nutrition, more than I knew before (interview 2) } \\
\text { It seems difficult for them (the staff) to obtain new scientific knowledge (interview 4) } \\
\text { It raised the level of consciousness, both for me and the patient (interview 5) }\end{array}$ \\
\hline $\begin{array}{l}\text { To live up to ethical } \\
\text { standards }\end{array}$ & $\begin{array}{l}\text { There was an ethical dilemma with a patient having dementia. The relatives were asked - and they } \\
\text { thought that it was important that this problem (nutrition) was highlighted (interview 1) } \\
\text { It is important that the assessment is followed by appropriate actions (interview 1) } \\
\text { I think a lot about the ethical. Not to violate. How does the care recipient wish it to be? You have to, } \\
\text { as work manager and nurse take action (interview 3) } \\
\text { I thought a lot about the ethical aspects - to gain informed consent (interview 3) }\end{array}$ \\
\hline $\begin{array}{l}\text { To work from a scientific } \\
\text { approach }\end{array}$ & $\begin{array}{l}\text { This research method can be used to improve the quality of care (interview 2) } \\
\text { It is important to have an understanding for research. Assessment instruments are important. } \\
\text { Scientific approach is the foundation. It is the nurses' task to keep themselves updated (interview 3) }\end{array}$ \\
\hline
\end{tabular}

\subsection{To be a foreman / supervisor}

The students cooperated with or supervised both student colleagues as well as other staff during the data collection. The participants who had implemented the project, together with students in the second semester or had engaged the ward staff in the project, felt that it had given them a good opportunity to practice the role of supervisor and foreman.

\subsection{To inform and engage in dialogue}

The students described their experiences from informing the staff about the study and how they engaged in dialogue mostly in positive terms. Giving feed-back of the project results to the staff was the students' responsibility. The feed-back was adapted for appropriate introduction to the current ward, such as at the morning meeting or a separate one. The participants felt that the medical staff mostly welcomed the project and were prepared to seriously discuss the outcomes and the proposed measures. One participant felt that the medical staff was positively confirmed in their ongoing work related to nutritional issues. Another respondent said that, for the nurses, the results of their assignment had highlighted the importance of making nutritional assessments. One student experienced however, that she got no feed-back from the staff or ward manager about the results. 


\subsection{To use risk assessment}

The students had different experiences from using structured assessments in clinical practice. Usually assessments were related to pain and wounds. Their experience was that instruments were sometimes used by routine, without reflection, and that the findings from the assessments were not always followed up. The participants discussed the importance of using assessment instruments to identify risks. They saw the structured assessment as a complement to their conversations with the patient, and that more penetrating questions were necessary in order to gain a complete picture of a patient's medical situation.

Students experienced that the patient's participation in the assessment was a prerequisite for a reliable result and it also increased the patient's awareness of any risk factors and appropriate measures to be taken in relation to their condition.

\subsection{To meet the person behind the diagnosis}

The patients were described by the students as very positive towards participating in the study. The patients were described as willing to contribute, that they felt especially attended to, and that it was a pleasant break for them. This was also described by students, to contribute to an open dialogue. The participants felt that, even if the assessment only took five to ten minutes per se to do, the situation offered an opportunity for deeper conversation that could lead to their increased knowledge and understanding of the patient as a person.

\subsection{To identify the need for knowledge}

The students identified both own knowledge-gaps as well as the need for the staff to acquire more knowledge. The participants experienced that they had gained new insight related to the importance, as a nurse, to have knowledge in, for example, nutrition. Knowledge gaps were identified and a curiosity to learn more was awakened. All of the participants described that taking part in the project had increased their awareness of the importance of measuring risks in health care. They also saw it as a task, in their role as a nurse, to be the person who initiates the use of risk assessments. When questions and issues arose that were to be discussed, the participants felt that this offered an important opportunity for them and their student colleagues, and also the ward staff, to acquire more knowledge. One respondent reflected over the difficulties for staff to get access to scientific knowledge.

\subsection{To live up to ethical standards}

The participants noted that it was important to ensure that the patient had really understood the verbal and written information they had been given regarding the purpose of the project, that participation was voluntary and that they had given their informed consent and were promised anonymity. The participants also talked about the importance of being aware of ethical issues in all their encounters with patients and that this approach was founded on the ethics and nursing supervision training they had been given, throughout the nursing degree programme. The participants also described how important it was not only to make an assessment but also to take preventive actions or begin treatment depending on whether or not there were risks.

\subsection{To work from a scientific approach}

The participants felt, that in their future profession as nurses, there would be a requirement for knowledge related to science and research and that it will be their personal responsibility to continuously keep abreast with new findings. Participation in the project was seen as an important part of their nursing training. The importance of taking a scientific approach was clarified for them by their involvement in the research project which had increased their knowledge of how research can be used and how quality working methods can be implemented in clinical practice. The participants saw the study design as a useful method within quality assurance work in their future profession. 


\section{Discussion}

The purpose of this study was to explore nursing students' experiences of participating in a research project during their clinical practice. The results showed that the participants felt strengthened in their role as nurses' inasmuch that they were independently responsible for the implementation of the study, worked as supervisors, and communicated their knowledge to other students and the medical staff. Participation was experienced as being involved in an important learning situation that gave insight into a nurse's responsibility for risk assessments and how improvement measures can be implemented in clinical practice. This is consistent with the Swedish National Board of Health and Welfare's description of the required competence for nurses, which states that a nurse should have the ability to lead and develop nursing care, supervise and train employees, develop quality and safety and promote continuous improvement ${ }^{[4]}$. To work with patient safety is an important factor in a nurse's area of responsibility. By participating in the research project the students' knowledge concerning reliable assessment instruments increased and further, their understanding of how these instruments can be used to identify health care risks. Injury preventive work in healthcare is highlighted in the Swedish Patient Injury Act ${ }^{\text {[24] }}$ which states that all health care professionals have a clear responsibility to work systematically with patient safety and the prevention of healthcare-related injuries. Nursing students' participation in a research project during their clinical practice courses provides them with valuable training for their future role as professional nurses, and further, the knowledge of how patient safety should be conducted. The knowledge gained by the students is a prerequisite for their performing good and safe care and helps to minimize patient suffering with its economic consequences for society.

By participating in a real research project, nursing students generate a greater understanding of the importance of working with a scientific and ethical approach. Prominent in the result of this study were the participants' reflections on ethical aspects in their meetings with patients, for example, through having a holistic view, standing up for patient autonomy, gaining the patients informed consent and their voluntary participation. Significant in the regulations governing health care is that health care professionals are required to base their medical work on science and proven experience. Furthermore, heath care shall be based on a holistic approach with respect for the individual patient's autonomy and privacy ${ }^{[24]}$. In a study conducted by Lilja and Edberg ${ }^{[25]}$, nurses were interviewed one year after graduation. Their results showed that students experienced the education related to science and research they had received, and further the training they had received during the nursing degree programme, to have proven invaluable to them in their current professional role. They had learned how to seek out, critically evaluate, and discuss new scientific findings. Furthermore, through their scientific knowledge they could question "truths" and participate in the development and improvement of care ${ }^{[25]}$. However, it is important not only to synthesise research findings but also to have the opportunity to actively participate in conducting research under supervision. Student involvement in research during clinical practice appears to offer them an important learning opportunity which generates a greater understanding of the importance of a scientific and ethical approach for their future professional role as nurses.

Collaboration between university education and clinical wards is encouraged when nursing students participate in a real research project during their clinical practice. Research, Education and Collaboration are integrated in the learning assignment during Nursing education (RECN-assignment, see Figure 1). It can even be an occasion to improve research utilisation and reduce the gap between theory and practice. Collaboration in this study was promoted by the staff being informed prior to the study, when, in some cases, the staff took part in data collection and when the results were reported and discussed with the staff. Papp and colleagues ${ }^{[26]}$ showed in their study about nursing students learning in clinical practice, that a good collaboration between the university and the clinical wards is important for a good learning environment where theory and practice complement each other. In another study, Stone and Rowles ${ }^{[27]}$ investigated how nursing students' research projects carried out during their clinical practice influenced the knowledge and work of the permanent staff of registered nurses. The results showed improved nursing practice and that the awareness of current research increased among the nurses. Nursing students' participation in the implementation of a real research project in clinical practice may be a way to combine research, education and collaboration which are the three pillars that Swedish higher education for nurses shall be based on ${ }^{[1]}$. 


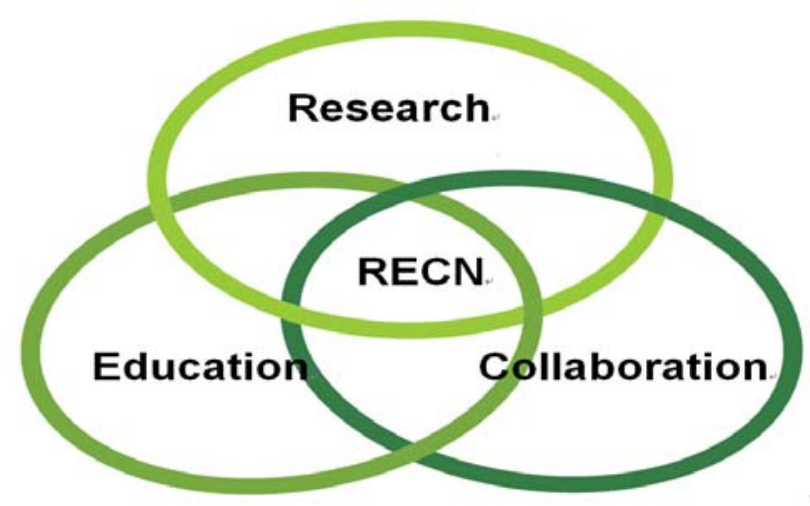

Figure 1. Research, Education and Collaboration integrated in a learning assignment during nursing education (RECN-assignment).

When planning and implementing qualitative studies, it is important to consider factors such as trustworthiness, credibility and transferability. A prerequisite for forming an opinion on trustworthiness is that all the steps in the research process are well described ${ }^{[17,22]}$. The participants in this study were recruited by clinical teachers and there is a risk that only those students who had mostly positive experiences from their having participated in the assignment agreed to take part in the study. The goal was however, to recruit both students that were positive as well as those that were negative towards the study.

To minimise the risk of researcher influence and to strengthen the trustworthiness of the results, the two authors independently read the texts several times, and then discussed their interpretations during each step of the analysis. To ensure that no data relating to the aim was excluded, the results were finally tested against the original texts ${ }^{\text {[22] }}$. The results are also supported by illustrative quotations that show details from the interview texts. Thus, several steps were conducted in order to increase the trustworthiness of the study.

\section{Conclusion}

It is possible to integrate education, research and collaboration by having nursing students participate in an actual research project during their work integrated learning courses. Such an approach enhances nursing students learning about research and the area being studied.

\section{Acknowledgements and funding}

The authors wish to thank the participating students for their cooperation. The study was conducted within the Patient-Reported Outcomes - Clinical Assessment Research and Education (PRO-CARE) Group, Kristianstad University, Sweden. The study was supported by the Swedish Research Council. Special thanks go to the Swedish house in Kavalla, Greece.

\section{Competing interests}

The authors declare that they have no competing interests'. 


\section{References}

[1] The Higher Education Act. Sweden, SFS. 1992: 1434.

[2] Swedish National Agency for Higher Education, Utvärdering av grundutbildningar i medicin och vård vid svenska universitet och högskolor. Del 2: Utbildningsbeskrivningar och bedömningar. Kvalitesgranskning. [In Swedish, Review of the quality of higher education in Sweden]. 2007; $23 \mathrm{R}$.

[3] The Health and Medical Services Act. Sweden, SFS. 1982; 763.

[4] Kompetensbeskrivning för legitimerad sjuksköterska [In Swedish, Competences required for registerd nurses], National board of health and welfare. 2005.

[5] Soop M, Fryksmark U, Köster M, Haglund B. The incidence of adverse events in Swedish hospitals: a retrospective medical record review study. Int J Qual Health Care. 2009; 21(4): 285-291. PMid:19556405 http//dx.doi.org/10.1093/intqhc/mzp025.

[6] Forsman H, Gustavsson P, Ehrenberg A, Rudman A, Wallin L. Research use in clinical practice - extent and patterns among nurses one and three years postgraduation. J Adv Nurs. 2009; 65(6): 1195-1206. PMid:19291193 http://dx.doi.org/10.1111/j.1365-2648.2008.04942.x.

[7] Estabrooks CA, Floyd JA, Scott-Findlay S, O'Leary KA, Gushta M. Individual determinants of research utilization: a systematic review. J Adv Nurs. 2003; 43(5): 506-520. PMid:12919269 http://dx.doi.org/10.1046/j.1365-2648.2003.02748.x.

[8] Kocaman G, Seren S, Lash AA, Kurt S, Bengu N, Yurumezoglu HA. Barriers to research utilisation by staff nurses in a university hospital. J Clin Nurs. 2010; 19(13-14): 1908-1918. PMid:20529164 http://dx.doi.org/10.1111/j.1365-2702.2009.03032.x.

[9] Thompson DS, O'Leary K, Jensen E, Scott-Findlay S, O'Brien-Pallas L, Estabrooks CA. The relationship between busyness and research utilization: it is about time. J Clin Nurs. 2008; 17(4): 539-548. PMid:18205684 http://dx.doi.org/10.1111/j.1365-2702.2007.01981.x.

[10] Meijers JM, Janssen MA, Cummings GG, Wallin L, Estabrooks CA, Y G Halfens R. Assessing the relationships between contextual factors and research utilization in nursing: systematic literature review. J Adv Nurs. 2006; 55(5):622-635. PMid:16907795 http://dx.doi.org/10.1111/j.1365-2648.2006.03954.x.

[11] Kajermo KN, Nordström G, Krusebrant A, Björvell H. Perceptions of research utilization: comparisons between health care professionals, nursing students and a reference group of nurse clinicians. J Adv Nurs. 2000; 31(1): 99-109. PMid:10632798 http://dx.doi.org/10.1046/j.1365-2648.2000.01255.x.

[12] Corlett J. The perceptions of nurse teachers, student nurses and preceptors of the theory-practice gap in nurse education. Nurse Educ Today. 2000; 20(6): 499-505. http://dx.doi.org/http://dx.doi.org/10.1054/nedt.1999.0414.

[13] Ax S, Kincade E. Nursing students' perceptions of research: usefulness, implementation and training. J Adv Nurs. 2001; 35(2): 161-170. PMid:11442695 http://dx.doi.org/10.1046/j.1365-2648.2001.01833.x.

[14] Lilja Andersson P, Edberg AK. Swedish nursing students' experience of aspects important for their learning process and their ability to handle the complexity of the nursing degree program. Nurse Edu Today. 2012; 32(4): 453-457. http://dx.doi.org/ http://dx.doi.org/10.1016/j.nedt.2011.05.011.

[15] Mattila LR, Eriksson E. Nursing students learning to utilize nursing research in clinical practice. Nurse Educ Today. 2007; 27(6): 568-576. http://dx.doi.org/10.1016/j.nedt.2006.08.018.

[16] Allan HT, Smith P. Are pedagogies used in nurse education research evident in practice? Nurse Educ Today. 2010; 30 (5): 476-479. http://dx.doi.org/10.1016/j.nedt.2009.10.011.

[17] Kvale S, Brinkman S. Interviews: Learning the craft of qualitative research interviewing (2nd ed). Los Angeles: Sage Publications. 2009.

[18] Downton JH, Andrews K. Prevalence, characteristics and factors associated with falls among the elderly living at home. Aging (Milano). 1991; 3(3): 219-228.

[19] Vallen C, Hagell P, Westergren A. Validity and user-friendliness of the minimal eating observation and nutrition form - version II (MEONF - II) for undernutrition risk screening. Food Nutr Res. 2011; 55. http://dx.doi.org/ 10.3402/fnr.v55i0.5801.

[20] Westergren A, Norberg E, Hagell P: Diagnostic performance of the Minimal Eating Observation and Nutrition Form - Version II (MEONF-II) and Nutritional Risk Screening 2002 (NRS 2002) among hospital inpatients - a cross-sectional study. BMC nursing. 2011; 10: 24. PMid:22185436 PMCid:3305676 http://dx.doi.org/ 10.1186/1472-6955-10-24.

[21] Westergren A, Norberg E, Vallen C, Hagell P: Cut-off scores for the Minimal Eating Observation and Nutrition Form - Version II (MEONF-II) among hospital inpatients. Food Nutr Res. 2011; 55. http://dx.doi.org/ 10.3402/fnr.v55i0.7289.

[22] Graneheim UH, Lundman B. Qualitative content analysis in nursing research: concepts, procedures and measures to achieve trustworthiness. Nurse Educ Today. 2004; 24(2): 105-112. http://dx.doi.org/ http://dx.doi.org/10.1016/j.nedt.2003.10.001.

[23] The Swedish Act concerning the Ethical Review of Research Involving Humans. Sweden, SFS. $2003 ; 460$.

[24] The Patient Injury Act. Sweden, SFS. 2010; 659. 
[25] Andersson PL, Edberg AK. The nursing programme in the rear-view mirror. Interviews with Swedish nurses one year after their graduation. Nurse Educ Today. 2010; 30(8): 747-751. http://dx.doi.org/10.1016/j.nedt.2010.01.017.

[26] Papp I, Markkanen M, von Bonsdorff M. Clinical environment as a learning environment: student nurses' perceptions concerning clinical learning experiences. Nurse Educ Today. 2003; 23(4): 262-268. http://dx.doi.org/10.1016/S0260-6917.

[27] Stone C, Rowles CJ. Nursing students can help support evidence-based practice on clinical nursing units. J Nurs Manag. 2007; 15(3): 367-370. PMid:17359437 http://dx.doi.org/ 10.1111/j.1365-2834.2007.00713.x. 